\title{
The role of the latency period in the preterm premature rupture of membranes: implications for treatment
}

Lin Lu, Jianhua Li, Bei Gan, Shan Zheng, Lihong Chen

Department of Obstetrics and Gynecology, The First Affiliated Hospital of Fujian Medical University, Fuzhou, China

Submitted: 3 May 2021, accepted: 24 June 2021

Online publication: 2 July 2021

Arch Med Sci

DOI: https://doi.org/10.5114/aoms/139314

Copyright $\odot 2021$ Termedia \& Banach

\section{Abstract}

Introduction: Conservative treatments with a latency period have been used for the treatment of preterm premature rupture of membranes (PPROM) in clinical practice. We aimed to evaluate the role and potential influencing factors of the latency period, to provide insights for the clinical treatment of PPROM.

Material and methods: PPROM pregnant women treated in our hospital from January 1, 2015 to September 30, 2020 were included. PPROM patients were divided into a 48-168 $\mathrm{h}$ group and a $>168 \mathrm{~h}$ latency group; the characteristics and prognosis of these two groups were compared and analyzed. Logistic regression analyses were conducted to analyze the relevant influencing factors of the latency period.

Results: A total of 131 PPROM patients were included. There were significant differences in the age, BMI, gestational age on admission, amniotic fluid volume before childbirth, and positive rate of cervical secretion culture between the two groups (all $p<0.05$ ). Logistic regression analyses indicated that the latency period was shorter in the PPROM patients with age $\geq 30$ years $(\mathrm{OR}=0.048,95 \% \mathrm{Cl}: 0.121-0.863)$ and gestational age $\geq 32$ weeks on admission ( $\mathrm{OR}=0.463,95 \% \mathrm{Cl}: 0.069-0.811)$, and the latency period was prolonged in the PPROM patients with $\mathrm{BMI} \geq 23 \mathrm{~kg} / \mathrm{m}^{2}(\mathrm{OR}=$ $1.591,95 \% \mathrm{Cl}: 1.134-1.944)$ and amniotic fluid volume $\geq 6 \mathrm{~cm}(\mathrm{OR}=2.129$, $95 \% \mathrm{Cl}: 1.093-3.042)$ (all $p<0.05)$. There were significant differences in the incidence of low birth weight and neonatal respiratory distress syndrome (NRDS) between the $48-168 \mathrm{~h}$ group and $>168 \mathrm{~h}$ group (all $p<0.05$ ).

Conclusions: The latency period plays an important role in PPROM, which is associated with the pregnant women's age, BMI, gestational week of rupture and amniotic fluid index.

Key words: premature rupture of membranes, preterm, latency period, care, treatment.

\section{Introduction}

Premature rupture of membrane (PROM) refers to the spontaneous rupture of fetal membranes before labor [1]. According to the gestational age at the time of occurrence, PROM is divided into preterm premature rupture of membranes (PPROM) and full-term premature rupture of membranes. PPROM occurs when the pregnancy is more than 20 weeks and less than 37 weeks. According to statistics [2, 3], the incidence of PPROM is $2.0-3.5 \%$, and $30-40 \%$ of preterm births are related to PPROM. PPROM can cause premature birth, placental abruption, oligohydram-

\author{
Corresponding author: \\ Lihong Chen \\ Department of \\ Obstetrics and \\ Gynecology \\ The First Affiliated \\ Hospital of Fujian \\ Medical University \\ 20 Chazhong Road \\ Taijiang District \\ Fuzhou City \\ Fujian Province \\ Fuzhou 350005 \\ China \\ Phone: 13645072616 \\ Fax: 0024078981023 \\ E-mail: \\ ucookyq0640226@163.com
}


nios, umbilical cord prolapse, fetal distress and neonatal respiratory distress syndrome (NRDS), intraventricular hemorrhage (IVH), and necrotizing enterocolitis (NEC), leading to higher perinatal morbidity and mortality [4-6]. Therefore, taking correct treatment measures for PPROM patients is crucial to reduce the perinatal complications and improve the prognosis of newborns.

It has been reported that for PPROM patients, the lower the gestational age is, the higher are the infection rates of pregnant women and fetuses and perinatal mortality [7]. Previous studies [8,9] have shown that prolonging the latency period for pregnant women with PPROM can reduce the infection rate of newborns, but it is difficult to attain a balance between prolonging the latency period and the timing of termination of pregnancy.

Therefore, we aimed to retrospectively evaluate the influencing factors of the latency period in pregnant women with PPROM, to provide insights for the clinical treatment and management of PPROM.

\section{Material and methods}

\section{Ethical concerns}

In this study, all methods were performed in accordance with the relevant guidelines and regulations. This study was checked and approved by the ethical committee of our hospital ([2016]005), all the included patients were well informed and written inform consent was obtained from patients.

\section{Patients}

We selected PPROM pregnant women admitted to our hospital from January 1, 2015 to September 30,2020 as the research population. The selection criteria of the patients in this study were as following: 1) patients were admitted to our hospital within $12 \mathrm{~h}$ after the occurrence of PPROM; 2) the gestational age of patients was 28 to 33 weeks ${ }^{+6}$ on admission; 3 ) pathological examination of the placenta, fetal membranes, and umbilical cord after delivery was performed in our hospital. Exclusion criteria were as follows: 1) The latency period after admission was less than $48 \mathrm{~h}$; 2) pregnant women with congenital abnormalities of the fetus; 3) patients who were unwilling to participate in this study. Patients with PPROM were divided into two groups according to the latency period after the occurrence of PPROM: the 48-168 h group and the $>168 \mathrm{~h}$ group.

\section{Treatment of PPROM}

We routinely used dexamethasone $5 \mathrm{mg}$ intramuscular injection, 1 time/ 12 h, 2 days to promote fetal lung maturity. At the same time, second-generation cephalosporins or azithromycin was used to prevent infection. For patients with $\geq 8$ uterine contractions within $60 \mathrm{~min}$, uterine pressure $\geq 60 \mathrm{~mm} \mathrm{Hg}$, and uterine orifice dilation $<3 \mathrm{~cm}$, magnesium sulfate, ritodrine hydrochloride, or nifedipine would be used with the patient's consent. All patients were monitored for leukocytes, C-reactive protein (CRP), and fetal heart rate every 3 days, and B-ultrasound monitoring and cervical secretion culture were performed once a week.

\section{Diagnostic criteria}

1) Oligo and oligohydramnios: B-mode ultrasound measurement of amniotic fluid index $(\mathrm{AFI}) \leq 8 \mathrm{~cm}$ was considered as oligohydramnios; 2) intrauterine infection: maternal fever $\geq 37.8^{\circ} \mathrm{C}$, accompanied by two or more of the following conditions: maternal pulse > 100 beats/min, white blood cell count >15 $\times 10^{9} /$ l, fetal heart rate > 160 beats/min, uterine tension and tenderness, smelly amniotic fluid, or positive amniotic cavity culture; 3) histology chorioamnionitis (HCA): in flammatory cell infiltration occurred in any tissue of chorionic membrane, amniotic membrane, and umbilical cord; 4) cervical secretion culture was positive. After PPROM occurred, we took a sterile swab to take the secretions from the cervix, and culture the bacteria, mycochlamydia, fungi, anaerobic bacteria, and gonococcus in our laboratory. For any culture with a positive result it was considered that the cervical secretion culture was positive. All the included patients received ceftriaxone sodium $2 \mathrm{~g}$ i.v. before delivery.

\section{Data collection}

Two investigators collected the following patients' information: age, body mass index (BMI), first pregnancy or not, the gestational age, white blood cells, amniotic fluid volume and CRP at the timepoint of admission and before childbirth. Additionally, we recorded the uterine contraction in hibitor use after $48 \mathrm{~h}$, results of cervical secretion culture, the incidence of intrauterine infection and HCA.

\section{Statistical analysis}

We used the SPSS 25.0 software package for statistical analysis. The measurement data were described using mean \pm standard deviation. The comparison between groups was performed by the two independent samples $t$-test or ranksum test. The count data were represented by rate, and the comparison between groups was performed by the $\chi^{2}$ test. With 0.05 as the level of selected variables and 0.10 as the level of excluded variables, forward step-by-step logistic 
regression analysis was used to analyze relevant influencing factors. $P<0.05$ indicated that the difference between groups was statistically significant.

\section{Results}

\section{Characteristics of included patients}

A total of 131 PPROM patients were included in this study. As presented in Table I, compared with the $>168 \mathrm{~h}$ group, there were significant differences in the age, BMI, gestational age on admission, amniotic fluid volume before childbirth, and positive rate of cervical secretion culture in the 48-168 h group (all $p<0.05$ ). There were no statistical differences in the first pregnancy, gestational age before childbirth, white blood cell, amniotic fluid volume on admission, CRP, uterine contraction inhibitor use after $48 \mathrm{~h}$, incidence of intrauterine infection and HCA between the 48$168 \mathrm{~h}$ group and $>168 \mathrm{~h}$ group (all $p>0.05$ ).

\section{Logistic regression analysis of the} influencing factors of latency period

We used global optimization logistic regression, took the latency period time as the dependent variable, and all other observed indicators as independent variables, and we used the Hosmer-Lemeshow test to detect the goodness of fit of the model. It was found that the age of pregnant women, the gestational age on admission and the latency period were negatively correlated. Also BMI and amniotic fluid volume were positively correlated with the latency period. As presented in Table II, we used forward stepwise logistic regression to analyze the influencing factors. It was found that the latency period was shorter in the PPROM patients with age $\geq 30$ years $(O R=0.048$, 95\% Cl: $0.121-0.863)$ and gestational age $\geq 32$ weeks on admission (OR $=0.463,95 \% \mathrm{Cl}$ : 0.069$0.811)$, and the latency period was prolonged in the $P P R O M$ patients with $B M I \geq 23 \mathrm{~kg} / \mathrm{m}^{2}(\mathrm{OR}=$

Table I. Characteristics of included patients

\begin{tabular}{|c|c|c|c|c|}
\hline Items & $48-168 \mathrm{~h}$ group $(n=68)$ & $>168 \mathrm{~h}$ group $(n=63)$ & $t / \chi^{2}$ & $P$-value \\
\hline Age [years] & $30.81 \pm 8.09$ & $25.53 \pm 7.16$ & 1.024 & 0.027 \\
\hline $\mathrm{BMI}\left[\mathrm{kg} / \mathrm{m}^{2}\right]$ & $24.72 \pm 2.55$ & $22.47 \pm 1.94$ & 1.217 & 0.014 \\
\hline First pregnancy & $38(55.88 \%)$ & $35(55.56 \%)$ & 1.108 & 0.092 \\
\hline \multicolumn{5}{|l|}{ Gestational age [weeks]: } \\
\hline On admission & $31.13 \pm 1.32$ & $31.56 \pm 1.60$ & 1.133 & 0.031 \\
\hline Before childbirth & $31.74 \pm 1.24$ & $31.89 \pm 1.39$ & 1.106 & 0.072 \\
\hline \multicolumn{5}{|l|}{ White blood cells $\left[\times 10^{9} / 1\right]$ : } \\
\hline On admission & $12.38 \pm 4.91$ & $11.95 \pm 4.14$ & 1.118 & 0.097 \\
\hline Before childbirth & $14.72 \pm 5.13$ & $14.68 \pm 6.01$ & 1.201 & 0.104 \\
\hline \multicolumn{5}{|l|}{ Amniotic fluid volume $[\mathrm{cm}]$ : } \\
\hline On admission & $7.63 \pm 4.35$ & $8.03 \pm 5.23$ & 1.186 & 0.092 \\
\hline Before childbirth & $4.290 \pm 2.31$ & $5.66 \pm 2.75$ & 1.159 & 0.034 \\
\hline \multicolumn{5}{|l|}{ CRP [mg/l]: } \\
\hline On admission & $5.69 \pm 4.11$ & $6.04 \pm 2.96$ & 3.137 & 0.121 \\
\hline Before childbirth & $24.08 \pm 10.27$ & $22.36 \pm 8.05$ & 6.223 & 0.076 \\
\hline $\begin{array}{l}\text { Uterine contraction } \\
\text { inhibitor use after } 48 \mathrm{~h}\end{array}$ & $61(89.71 \%)$ & $50(79.37 \%)$ & 1.303 & 0.116 \\
\hline $\begin{array}{l}\text { Positive cervical secretion } \\
\text { culture }\end{array}$ & $21(30.88 \%)$ & $24(38.09 \%)$ & 1.125 & 0.044 \\
\hline Intrauterine infection & 7 (10.29\%) & $7(11.11 \%)$ & 1.203 & 0.089 \\
\hline $\mathrm{HCA}$ & $56(82.35 \%)$ & $51(80.95 \%)$ & 1.167 & 0.105 \\
\hline
\end{tabular}

Table II. Logistic regression analysis of the influencing factors of latency period in the PPROM patients

\begin{tabular}{|lccccc|}
\hline Variables & $\beta$ & Wald & OR & 95\% Cl & $P$-value \\
\hline Age $\geq 30$ years & -0.153 & 2.127 & 0.048 & $0.121-0.863$ & 0.042 \\
\hline Gestational age $\geq 32$ weeks on admission & -0.122 & 1.199 & 0.463 & $0.069-0.811$ & 0.025 \\
\hline BMI $\geq 23 \mathrm{~kg} / \mathrm{m}^{2}$ & 0.113 & 2.037 & 1.591 & $1.134-1.944$ & 0.038 \\
\hline Amniotic fluid volume $\geq 6 \mathrm{~cm}$ & 0.101 & 3.115 & 2.129 & $1.093-3.042$ & 0.018 \\
\hline
\end{tabular}


Table III. Comparison of prognosis of newborns between $48-168 \mathrm{~h}$ and $>168 \mathrm{~h}$ groups

\begin{tabular}{|lcccc|}
\hline Items & 48-168 h group $(n=68)$ & $>168 \mathrm{~h}$ group $(n=63)$ & $t / \chi^{2}$ & $P$-value \\
\hline Low birth weight & $32(47.06 \%)$ & $36(57.12 \%)$ & 1.327 & 0.011 \\
\hline NRDS & $12(17.65 \%)$ & $3(4.76 \%)$ & 1.105 & 0.043 \\
\hline Pneumonia & $35(51.47 \%)$ & $33(52.38 \%)$ & 1.041 & 1.294 \\
\hline Sepsis & $14(20.59 \%)$ & $11(17.46 \%)$ & 1.217 & 0.098 \\
\hline IVH & $20(29.41 \%)$ & $20(31.75 \%)$ & 1.454 & 0.102 \\
\hline HIE & $31(45.59 \%)$ & $29(46.03 \%)$ & 1.049 & 0.079 \\
\hline NEC & $12(17.65 \%)$ & $11(17.46 \%)$ & 0.079 \\
\hline
\end{tabular}

1.591, 95\% Cl: 1.134-1.944) and amniotic fluid volume $\geq 6 \mathrm{~cm}(\mathrm{OR}=2.129,95 \% \mathrm{Cl}: 1.093-3.042)$ (all $p<0.05$ ).

\section{Prognosis of newborns}

As indicated in Table III, there were significant differences in the incidence of low birth weight and NRDS between the 48-168 $\mathrm{h}$ group and $>168 \mathrm{~h}$ group (all $p<0.05$ ), and no significant differences in the incidence of pneumonia, sepsis, IVH, hypoxic-ischemic encephalopathy (HIE), or NEC were found (all $p>0.05$ ).

\section{Discussions}

At present, the specific mechanisms of PROM are not fully understood. Studies [10-12] have shown that bacterial vaginitis, urinary tract infection, smoking during pregnancy, history of premature rupture of membranes, sexually transmitted diseases, abnormal cervical function, polyhydramnios, and invasive procedures are risk factors for premature rupture of membranes, among which genital tract infection has been considered to be the main cause of premature rupture of membranes. The hormone levels and immunity of pregnant women have changed, and their susceptibility to a variety of pathogens has increased, and they are susceptible to infection with these pathogens [13-15]. As an active immune site, the placenta can cause inflammation and an immune response under the action of pathogenic bacteria, and promote the production and release of a variety of inflammatory cytokines [16, 17]. The maternal immune system is activated in this environment, resulting in damage to the placenta, causing adverse pregnancy outcomes such as premature birth [18]. Studies [19, 20] have found that the detection rate of bacteria in the amniotic fluid for PROM reaches $30 \%$, and another $70 \%$ of patients may also be infected by the living maternal tissues of amniotic fluid. Therefore, the early diagnosis and timely treatment are vital to the prognosis of PROM patients.

We have found that the earlier the gestational week of the PPROM is, the longer is the latency period, which is consistent with the results of previous studies [21, 22], and the pregnant women whose membrane rupture occurs before 32 weeks have a greater probability of a latency period $>168 \mathrm{~h}$. It has been reported [23] that expecting a time longer than 1 week does not increase the risk of HCA, so pregnant women who have ruptured membranes before 32 weeks should keep the latency period more than one week. There are still many controversies about the relationship between the number of pregnancies, age and latency period of pregnant women. The results of this study show that the patient's parity is not a risk factor that affects the latency period, which is consistent with the results of previous studies $[24,25]$. It has been reported that gestational age is closely associated with preterm premature rupture of membranes [26, 27]. Pregnant women over the age of 30 have an increased probability of shortening the latency period. It is estimated that different medical institutions have biases in the selection of the latency period. Yet the specific latency period requires large-scale, multi-centered research in the future.

In our study, the amniotic fluid index of the two groups of patients is not statistically significantly different at admission, but during the latency period, when the amniotic fluid index is above $6 \mathrm{~cm}$, the possibility of a latency period $>168 \mathrm{~h}$ increases accordingly. The possible reasons may be as follows: rupture of the membrane leads to the fetal head getting closer to the lower part of the uterus, which has a mechanical expansion effect on it, causing the start of labor [28]. Also, the fetus gets closer to the uterine wall, the umbilical cord is compressed, the incidence of fetal distress increases, and the termination of pregnancy is early [29-31]. The amniotic fluid volume of pregnant women is closely related to infection. Infection places the fetus in a state of stress, reduces blood flow in the kidneys and urine output, and reduces amniotic fluid volume [9]. Amniotic fluid contains a variety of anti-infective cytokines, and the loss of amniotic fluid weakens the capacity for resistance to infection, thereby aggravating intrauterine infections, which can easily induce contractions [32, 
33]. Therefore, for pregnant women with PPROM with progressive reduction in amniotic fluid, even if there is no clinical evidence of infection, they must be highly vigilant for the occurrence of chorioamnionitis [34].

Previous studies have reported [35-37] that for PPROM patients who have fetal lung maturity and infection, simply extending the gestational period will not reduce the serious complications of preterm infants, but PPROM pregnant women have reduced amniotic fluid, higher incidence of chorioamnionitis and various inflammations in the amniotic fluid. The increase in substances can affect the growth and development of the fetus, causing the fetal body mass not to increase correspondingly with the increase of the gestational age. The more the gestational age increases, the more the fetal body mass lags behind [38]. We have found that extending the gestational age does not reduce the incidence of serious complications of preterm infants and maternal infectious diseases, and the use of uterine contraction inhibitors does not help to extend the gestational age. Therefore, for PPROM patients, the focus should be on predicting and treating infections. For patients with increased WBC, progressive increase in CRP, and progressive decrease in amniotic fluid, even if intrauterine infection cannot be diagnosed clinically, a comprehensive assessment should be combined with the specific conditions of the patient. It has been reported that intrauterine infection is thought to be one cause of PPROM, and use of antibiotic regimens is beneficial for the control of intrauterine infection and reduction of infant morbidity [39, 40]. Still, the timing and dose of antibiotic regimens in the PPROM require further investigations.

In conclusion, we have found that for PPROM patients, pregnant women's age, BMI, gestational week of rupture and amniotic fluid index are associated with the latency period. With a longer latency period, the incidence of NRDS is lower, but the incidence of low birth weight is higher. As this study is limited by sample size and study design, future studies with a larger sample size and prospective design are needed to further elucidate the potential influencing factors of the latency period, to provide evidence for the management of PPROM.

\section{Acknowledgments}

Lin Lu and Jianhua Li - equal contributor.

This study has been funded by Industry-University-Research Project of Fujian Provincial Department of Education (JAT160189). The funders had no role in study design, data collection and analysis, decision to publish, or preparation of the manuscript.

\section{Conflict of interest}

The authors declare no conflict of interest.

\section{References}

1. Areia AL, Areia M, Mota-Pinto A. Procalcitonin in preterm rupture of membranes: a systematic review and meta-analysis. Arch Gynecol Obstet 2021; 303: 917-24.

2. Volpe N, di Pasquo E, Ferretti A, et al. Hyperechoic amniotic membranes in patients with preterm premature rupture of membranes ( $p-P R O M)$ and pregnancy outcome. J Perinat Med 2021; 49: 311-8.

3. Niyaty S, Moghaddam-Banaem L, Sourinejad H, Mokhlesi S. Are maternal metabolic syndrome and lipid profile associated with preterm delivery and preterm premature rupture of membranes? Arch Gynecol Obstet 2021; 303: 113-9.

4. Shiqiao H, Bei X, Yudi G, Lei J. Assisted reproductive technology is associated with premature rupture of membranes. J Matern Fetal Neonatal Med 2021; 34: 555-61.

5. Maged AM, Kamel HH, Sanad AS, et al. The value of amniopatch in pregnancies associated with spontaneous preterm premature rupture of fetal membranes: a randomized controlled trial. J Matern Fetal Neonatal Med 2021; 34: 267-73.

6. Pierson RC, Gordon SS, Haas DM. A retrospective comparison of antibiotic regimens for preterm premature rupture of membranes. Obstet Gynecol 2014; 124: 515-9.

7. Huang CC, Pan SC, Chin WS, et al. Maternal proximity to petrochemical industrial parks and risk of premature rupture of membranes. Environ Res 2021; 194: 110688.

8. Zhang SE, Chen XY, Chen C, Qiu XM, Lin BC, Yang CZ. Influence of premature rupture of membranes on the early prognosis of extremely premature infants. Zhongguo Dang Dai Er Ke Za Zhi 2021; 23: 25-30.

9. Kole-White MB, Nelson LA, Lord M, et al. Pregnancy latency after preterm premature rupture of membranes: oral versus intravenous antibiotics. Am J Obstet Gynecol MFM 2021; 3: 100333.

10. Rouzaire $M$, Corvaisier M, Roumeau V, et al. Predictors of short latency period exceeding $48 \mathrm{~h}$ after preterm premature rupture of membranes. J Clin Med 2021; 10: 150.

11. Liu Y, Wu M, Song L, et al. Association between prenatal rare earth elements exposure and premature rupture of membranes: results from a birth cohort study. Environ Res 2021; 193: 110534

12. Suff N, Kunitsyna M, Shennan A, Chandiramani M. Optimal timing of cervical cerclage removal following preterm premature rupture of membranes; a retrospective analysis. Eur J Obstet Gynecol Reprod Biol 2021; 259: 75-80.

13. Wolfensberger A, Zimmermann R, von Mandach U. Neonatal mortality and morbidity after aggressive longterm tocolysis for preterm premature rupture of the membranes. Fetal Diagn Ther 2006; 21: 366-73.

14. Medina TM, Hill DA. Preterm premature rupture of membranes: diagnosis and management. Am Fam Physician 2006; 73: 659-64.

15. Sae-Lin P, Wanitpongpan P. Incidence and risk factors of preterm premature rupture of membranes in singleton pregnancies at Siriraj Hospital. J Obstet Gynaecol Res 2019; 45: 573-7.

16. Mehra S, Amon E, Hopkins S, Gavard JA, Shyken J. Transvaginal cervical length and amniotic fluid index: can it predict delivery latency following preterm premature 
rupture of membranes? Am J Obstet Gynecol 2015; 212 : 400e1-9.

17. Tchirikov M, Schlabritz-Loutsevitch N, Maher J, et al. Mid-trimester preterm premature rupture of membranes (PPROM): etiology, diagnosis, classification, international recommendations of treatment options and outcome. J Perinat Med 2018; 46: 465-88.

18. Schmitz T, Sentilhes L, Lorthe E, et al. Preterm premature rupture of the membranes: Guidelines for clinical practice from the French College of Gynaecologists and Obstetricians (CNGOF). Eur J Obstet Gynecol Reprod Biol 2019; 236: 1-6.

19. Sim WH, Ng H, Sheehan P. Maternal and neonatal outcomes following expectant management of preterm prelabor rupture of membranes before viability. J Matern Fetal Neonatal Med 2020; 33: 533-41.

20. Guckert M, Clouqueur E, Drumez E, et al. Is homecare management associated with longer latency in preterm premature rupture of membranes? Arch Gynecol Obstet 2020; 301: 61-7.

21. Musilova I, Andrys C, Hornychova H, et al. Gastric fluid used to assess changes during the latency period in preterm prelabor rupture of membranes. Pediatr Res 2018; 84: 240-7.

22. Yagur Y, Weitzner O, Ravid E, Biron-Shental T. Can we predict preterm delivery in patients with premature rupture of membranes? Arch Gynecol Obstet 2019; 300: 615-21.

23. Mei-Dan E, Hutchison Z, Osmond M, Pakenham S, Ng E, Green J, Nevo O. Preterm premature rupture of membranes in twins: comparison of rupture in the presenting versus non-presenting sac. J Obstet Gynaecol Can 2020; 42: 163-8.

24. Phupong V, Kulmala L. Factors associated with latency period in preterm prelabor rupture of membranes. J Matern Fetal Neonatal Med 2016; 29: 2650-3.

25. Ilhan N, Aygun BK, Gungor H. The relationship between the latency period, infection markers, and oxidant and antioxidant states in women with preterm premature rupture of membranes. Ir J Med Sci 2017; 186: 965-70.

26. Gibson KS, Brackney K. Periviable premature rupture of membranes. Obstet Gynecol Clin North Am 2020; 47: 633-51.

27. Swiatkowska-Freund M, Traczyk-Los A, Partyka A, Obara K, Damdinsuren A, Preis K. Perinatal outcome in preterm premature rupture of membranes before 37 weeks of gestation. Ginekol Pol 2019; 90: 645-50.

28. Snowise S, Mann LK, Moise KJ Jr, Johnson A, Bebbington MW, Papanna R. Preterm prelabor rupture of membranes after fetoscopic laser surgery for twin-twin transfusion syndrome. Ultrasound Obstet Gynecol 2017; 49: 607-11.

29. Workineh Y, Gultie T. Latency period and early initiation of breastfeeding in term premature rupture of membrane in Southern Ethiopia, 2017. Ital J Pediatr 2019; 45: 70.

30. Schreiber H, Shitrit P, Man-El G, Engel O, Berkovitz A, Biron-Shental T. Macrolide antibiotics roxithromycin vs. azithromycin for preterm premature rupture of membranes: a retrospective comparison. Arch Gynecol Obstet 2019; 300: 569-73.

31. Choi EK, Kim SY, Heo JM, et al. Perinatal outcomes associated with latency in late preterm premature rupture of membranes. Int J Environ Res Public Health 2021; 18: 672.

32. Di Sarno R, Raffone A, Saccone G. Effects of progestogens in women with preterm premature rupture of membranes. Minerva Ginecol 2019; 71: 121-4.
33. Walker MW, Picklesimer AH, Clark RH, Spitzer AR, Garite TJ. Impact of duration of rupture of membranes on outcomes of premature infants. J Perinatol 2014; 34 669-72.

34. Sorano S, Fukuoka M, Kawakami K, Momohara Y. Prognosis of preterm premature rupture of membranes between 20 and 24 weeks of gestation: a retrospective cohort study. Eur J Obstet Gynecol Reprod Biol X 2020; 5: 100102.

35. Test G, Levy A, Wiznitzer A, et al. Factors affecting the latency period in patients with preterm premature rupture of membranes. Arch Gynecol Obstet 2011; 283: 707-10.

36. Galletta MAK, Bittar RE, Agra I, Guerra ECL, Francisco RPV, Zugaib M. Epidemiological profile of patients with preterm premature rupture of membranes at a tertiary hospital in Sao Paulo, Brazil. Clinics 2019; 74 e1231.

37. Catt E, Chadha R, Tang S, Palmquist E, Lange I. Management of preterm premature rupture of membranes: a comparison of inpatient and outpatient care. J Obstet Gynaecol Can 2016; 38: 433-40.

38. Kacerovsky M, Romero R, Stepan M, et al. Antibiotic administration reduces the rate of intraamniotic inflammation in preterm prelabor rupture of the membranes. Am J Obstet Gynecol 2020; 223: 114e111-20.

39. Mercer BM, Miodovnik M, Thurnau GR, et al. Antibiotic therapy for reduction of infant morbidity after preterm premature rupture of the membranes. A randomized controlled trial. National Institute of Child Health and Human Development Maternal-Fetal Medicine Units Network. JAMA 1997; 278: 989-95.

40. Martingano D, Singh S, Mitrofanova A. Azithromycin in the treatment of preterm prelabor rupture of membranes demonstrates a lower risk of chorioamnionitis and postpartum endometritis with an equivalent latency period compared with erythromycin antibiotic regimens. Infect Dis Obstet Gynecol 2020; 2020: 2093530. 